\title{
Key Success Factors of Enterprise Importing ERP System-Taking Electronic Information Motherboard Manufacturing Company as an Example
}

\author{
Chu Fang \\ Beijing Institute of Technology, Zhuhai
}

\begin{abstract}
This paper first gathers and analyzes the relevant literature to understand methods for successful implementation of ERP system. Next, it deeply investigates the methodology as well as the development process of a local motherboard manufacturing company. In this study, some in-depth interviews are conducted to the project members including personnel of the information department and the counseling company. This research also analyzes relevant issues relating to the ERP implementation and operation of this case company by means of direct observation. It also compares the differences of system development processes and key project factors between the case company and the best practice company from Oracle. Though the above discusses, we can reach two conclusions on this study: (1) There is a high-level correlation between the well organizational structure and the success of ERP implementation, (2) The strong support from the ERP consulting company is a critical factor for the company to implement the system successfully.
\end{abstract}

Keywords-Customer relationship management (CRM); Business process reengineering; Case study; System implementing

\section{INTRODUCTION}

Wang Yi pointed out that ERP is not a new one, but follow the early material requirements planning and manufacturing resource planning concept, further integration of the various departments of information, so that the operators can get realtime information and decision makers like 1, which evolved into ERP.1970-1980 years, Belong to the producer oriented mass market, focusing on market demand function and the cost of products, so the key management organizations to set a cap and to reduce production costs, the application of this era of information system is based on MRP and MRP II mainly focus on production and material planning and integration of external sales and financial operations [1]. 1980-1990 years, The market is gradually entering the era of consumer orientation. Product demand diversification and quality requirements lead to the diversification of production mode and dispersed production mode. At this time, information system application is MRP. 1990-2000 years ,Mass variation (Mass Variation) production mode, emphasis on flexibility, reaction and effective application of the whole resources of the ERP system; so the definition of the ERP system is the enterprise internal and external resources, including all research and development, sales, production, distribution, service and finance, through the organization, process, management and information technology integration, and effective with the application of elasticity to achieve rapid strain and competitive work [2].

Entering the millennial era of global division and competition in twenty-first Century [3], internal resource integration is not enough to express the demand of global competition. Enterprises must strengthen their ERP system and integrate Supply Chain Management (SCM) system function and Internet.

Web and Working Flow technology, in order to effectively combine external resources [4], form a virtual competitive entity, in order to meet the future global competition and the change of e-commerce.

Davenport and Short of the false statement pointed out that the core structure of ERP database system for the enterprise , the company responsible for collecting data generated by the operation of each system, and the information feedback system required. Therefore, using a single database connection, will enable enterprises to simplify the full process of data [5].

Bingi that the information system ERP system for 1 integration of all business activities within the enterprise and the enterprise as a whole; by single 1 database application system, and the same interface (Interface) combination will enable each function over enterprise resources, accounting, sales, manufacturing, distribution and supply chain management closely [6].

The information system is defined as helping to collect, process, store, and transmit information to assist the decision making of the enterprise.

ERP is the essence of the above transaction processing system one line (OLTP--On Line Transaction Processing); and the difference between the system of traditional data processing, real-time (Real Time) and integration (Integration). ERP through the integration of various departments to produce data process [7].

The above basic, ERP software is designed according to the work flow, work flow and real-time supply optimization concept. Make the most effective use of enterprise resources, reduce repetition, idle and wait, and then shorten the production time [8]. 


\section{CASE ANALYSIS}

First to collect the background information of the case company and to get a preliminary understanding of the company's current situation. Draft for the question and the scheduled interview time and object, including the Ministry of information management and project team members, as well as import, line your actual operation I member etc.. The content of the interview is not only to confirm the previously collected data, but also to discuss the problems encountered by the company. Then the scene of the operation to direct observation, with over 1 step into do interviews, to understand the reasons for the phenomenon. In addition, the company also made part of your license, related documents and records.

In this study, in the primary data, it is the way of in-depth interview and direct observation. In the secondary data, including research and information related to the ERP system, and the company archives and records, you have to collect the data of the research steps are introduced.

In-depth interview, First of all, it contacted the supervisor of the case of the interview and consulted his willingness to interview. If he agrees, he will confirm the time of the interview and the object of the interview to the supervisor of the interview [9], because the information obtained by the students has been served in the case company, so the information obtained is more convenient. The content of the talk is mainly based on questionnaires, assisted by recording, so that after finishing the interview, data can be collected quickly. If the interviewees do not want to record, they will take notes instead of them, so as to avoid respondents' hesitation when answering questions [10], which makes the information acquisition is not authentic. Two places were invited to the interview.

Those respondents participate at the same time, in the interview process either, for the same problem when asked 1, 1 respondents answered, then please the other 1 respondents answered the same 1 problem, such as This can avoid the single 1 the opinions of the respondents will be biased. Must be noted in the interview records above.

Follow up observation. The interview records, do analysis and comparison work immediately, and 1 step out A question that is not yet clear or suspicious. After the appointment of the interviewee, the interview was conducted again. In the interview process either, the beginning must confirm the content of the interview with the respondents above times soon 1 , the respondents have an impression on the theme of the study. Then the interviewees were interviewed with the interviewees.

The sorting and confirmation of records. Whether it is an interview or a record of observation, it must be funded after finishing. The material is encoded and archived as the most original material; and the interviewee must be sent to the interviewee to reconfirm it before filing to ensure that the information is correct.

Write the report: Collate the related interview materials and records, and complete the interview report.
The company was founded in 1986, the Taiwan main board factory 1, main products at this stage include the main board, VGA display and Barebone System, a complete system of marketing in 20 countries around the world to provide the best customer service, and based in Holland, UK, USA, France, Germany and China, either where such branch create a world of enterprise team, since the founding of the company is committed to product self development, cultivate a group of 1 natural product development technology 1 Flow Design Engineer, to conform to the trend of the times and needs of the product, provide the world computer lover stable high value use environment.

This study is based on the introduction of SAP method as a reference, comparison method and case guidance and import manufacturers actual, in order to analyse the import method above have deficiencies and problems, which cause the failure, the details as below:

1, Start planning: The method of implementation of ERP on either ASAP, the primary stage is the first stage of project preparation, project IEERP is ready, and the two methods on both planning and planning of pre operation, this study mainly explores the IEERP occurred in the beginning part of the planning and preparation of open questions, and to examine the case company whether it is suitable for the introduction of a ERP system. The lack of sufficient support from top executives is the main reason for the failure of ERP. The reason is that the complete plan is not introduced, but the mentality of walking around. Moreover, the incongruity of the members of the organization and the lack of consensus are the main reasons.

The definition of success has 2 levels: 1 is the system in accordance with the plan above line; 1 is the system to show the expected benefit of the above line. ERP vendors and consultants may be more concerned about the latter, but for enterprises, the former is the important goal of importing ERP, which is also the definition of the successful introduction of ERP.

Comprehensive measurement method of the above variables, through actual interviews, in-depth observation, to analyze the real reason of the import failed. And whether the system can succeed the above lines mean system existence value. If the enterprise purchase 1 system, but can not play its function and benefit of enterprises is nothing but a waste of resources [11].

Find different enterprises to verify whether the problems encountered in the actual introduction of this study are similar.

Based on the framework and results of this study, the relevant issues related to the actual introduction of the other modules of the ERP system are quantified.

Due to limited time and with the intention of this study, 3 manufacturers, unable to do more in-depth excavation for all the factors of change, further research if the objective conditions permit, can further discuss the related problems more widely [12].

Choose to help manufacturers: when manufacturers need counseling support and assistance, whether it is your line. Service, or assistance, can give the greatest help in the shortest possible time. System customization flexibility: the 
customization flexibility of the system enables $\mathrm{C}$ company to customize and modify based on the characteristics of the process, and it will not be limited by the system structure and can not play the system efficiency. Project management, planning and program schedule: the above line ERP into the stage as one project, from the above line plan, for each stage of your line procedure strictly according to the plan, and keep contact manufacturers and guidance to ensure the progress of an effective.

Held a regular review meeting: in the process of computerized counseling and counseling team either, because computer manufacturers will discuss the system either has not yet reached the optimum. Is it unreasonable to work? Or is it not deep enough to understand the new system? Through regular review meetings, find out the problem and put forward a reasonable solution [13].

In the first part of the development of the proposition, the continuation of the above section 1 Analysis of the contents of the case, according to Article 3 chapter research framework, explore some theoretical references, the key to the successful implementation of the ERP system ERP enterprise either factors and company for forming a reasonable inference, the development of an important proposition mode.

Proposition 1: understanding the needs of itself does not have a significant relationship with the success of the introduction

It is concluded that $\mathrm{C}$ company is really aware of its needs at the time when it sought information technology solutions. But after importing, it found many duplicate parts of the existing process, but considering the interests of related units, it did not implement the action of process reengineering.

Proposition 2: the strong support of the senior executive has no significant relationship with the success of the introduction

Concluded the executives of $\mathrm{C}$ company was required to support the form, but in the process of introducing ERP cap, by tissue rejection, so many barriers to the implementation of ERP.

Proposition 3: there is no significant relationship between the full communication of various departments and the success of the introduction

Inductive inference in C company just imported, is actively communicating with various departments, but did not reach every employee can support ERP goals; and each department said the beginning can be completely fit, but 1 encounter conflicts of interests, will resist mentality. Proposition 4: the direction of the company, the clear strategy and the success of the introduction do not have a significant relationship The company has just begun $\mathrm{C}$ inductive inference are clearly formulated to promote the direction and specific policy rules, but reached the purpose, to promote, who is who is responsible for, what priority no definite plan. Proposition 5: there is no significant relationship between inductive inference of high order $\mathrm{C}$ executives are beginning to have issued a notice of the driving force and strong implementation success above level managers, for all employees That you want to import the full support of the ERP, but because the departmentalism of each department is too heavy, the above layer support become a challenge. Proposition 6: support and import successful line supervisor has no obvious relationship. Inductive inference $\mathrm{C}$ company line supervisor is responsible for teaching those seeds into ERP, but your online supervisor has to fully cooperate with the company policy consensus, but because in training is not your line supervisor, but workers or employees, finally, will lead to teach and education training results can not be implemented.

Proposition 7: the project execution team does not have a significant relationship with the success of the introduction. The conclusion is that $\mathrm{C}$ company has set up a project execution team, but it is implemented. Your participation in this member is not implemented, mostly for information that, while the use of units and project managers are not in.

Proposition 8: the monitoring mechanism does not have a significant relationship with the success of the introduction. It is concluded that $\mathrm{C}$ company has a unit to set up a monitoring mechanism, but this unit and Not to be monitored in a full-time job, but to be attached to a unit, which will form a control effect.

The result is reduced, and the rejection mentality of the executive unit will also appear. Proposition 9: there is no significant relationship between the correctness of the data and the success of the introduction The Ministry of information has inductive inference in the transfer of data is correct, but in the relevant work units did not fully cooperate with the data set of table below, errors often occur, the basic data set becomes difficult.

The result is reduced, and the rejection mentality of the executive unit will also appear. Proposition 9: there is no significant relationship between the correctness of the data and the success of the introduction The Ministry of information has inductive inference in the transfer of data is correct, but in the relevant work units did not fully cooperate with the data set of table below, errors often occur, the basic data set becomes difficult.

Proposition 1: use ERP software vendors and successfully no significant relationship

The inductive inference is that $\mathrm{C}$ companies are generally not familiar with the software functions of all ERP providers. Moreover, C companies generally fail to recognize the importing of ERP systems by software vendors. In fact, want to use the ERP software vendors is the key point in the market, above there are many ERP software vendors claim to successfully import ERP, but the real key point of software vendors can evaluate whether there are enough experience and ability, is the consultant's quality, software manufacturers with high degree, the success of education and training teaching material, whether the system can fit and efficient logistics support. And choosing the wrong software vendors will cost the company a huge cost and time, and cause the failure of the system import.

Proposition 2: there is no significant relationship between the successful communication with the consultant company and the success of the introduction. Concluded the $\mathrm{C}$ company will communicate with the consultant, but these. 
Proposition 2: there is no significant relationship between the successful communication with the consultant company and the success of the introduction. Concluded the $\mathrm{C}$ company will communicate with the consultant, but these.

When the general manager of a case company started importing ERP, it was full of interest. The reason was that considering the receipt of OEM and ODM, many foreign customers asked the seller to have the experience of importing ERP, so the general manager just wanted to import the ERP system. But the ERP system is not into 1 will succeed and, this is related to many factors, with the enterprise culture and staff. Speaking of leadership, high level executives didn't wholeheartedly import ERP system, but only wanted to know more about orders from foreign customers when they had imported ERP system, but the final result was the failure of import.

The case method of qualitative analysis to several points below: 1. Literature analysis (1) secondary information published by a manufacturer or scholar (2) ERP related website information (3) 2. Where observation of Internet News. The researchers contact related work, in the work process is either to explore topics to do .To observe, and to know more about interviewees in depth interviews. Where is the main source of real observation 2: 1 for the introduction of ERP in the system as an engineer in C company, the company named ERP C 2 to participate in the meeting and the process of software, and the education and training of the import side observation. 3. Deep interview. With the need to study the process of either the design interview questions to interview respondents, hope that through this process, a more in-depth discussion on the problem.

\section{CONCLUSION}

The main contribution of this study is a part of 2 :

(1) Let the enterprise very clear in the introduction of ERP, either all the import process problems, thereby reducing the risk of ERP implementation failure.

(2)Based on the introduction of ERP company as the interview object, either from the organization that member of the different point of view, discusses the introduction and use of the process approach, and the problems and difficulties encountered, for enterprises as a reference system into ERP.

\section{REFERENCES}

[1] Bingi,P.,M.Sharma and Godla,K.,"Critical Issues Affectig an ERP Implementation", Information Systems management,Summer,1999, pp.7-14.

[2] Dave,M.,"Full speed ahead”, CMA Management,Hamilton,Nov.2000, pp.34-36.

[3] Davenport,T.,and J.Short,"Putting the enterprise into the enterprise system”, Harvard business review,Jul.-Aug.,1998, pp.121-131.

[4] Desanctis,G.,and J.F.Gourtney, "Toward Friendly User MIS Implementation",Communication of the ACM,Vol.26,No.10,1983.

[5] Jeff,S., "Learnig Curve”, Information Week, Aug.1999, pp.44-52. 6 、 Kip,R.K.,and G.J.Win, "Reaping the promise of enterpriseresource systems", Strategic Finance, Montvale,Oct.2000, pp.48-52.

[6] Leslie,W.,and S.Richard,"The role of the CIO and IT function in ERP”,Vol.43,Communications Of The ACM, Apr.2000, pp.32-38.

[7] Marketing management - Asian example] author: Philip Kotler / Siew Meng Leong / Swee HoonAng/Chin Tiong Tan). (In Chinese)

[8] Laudon,K., and J.Laudon,"Management information systems", Prentice Hall, 1998.

[9] Mccaan,S., “Quick Study ERP”, Computerworld, September 14,1998,pp.63.

[10] Stephen,P.L., “An ERP Game Plan”, Journal of Business Strategy, January/February, 1999,pp.36.

[11] Stephen,P.L.,"An ERP Game Plan”, Journal of Business Strategy, January/February,1999,pp.36.

[12] Vasilash,G.S.,"How to-and How Not to-Implement ERP", Automotive Manufacturing \& Production,Vol.109,Iss.8,1997, pp.64-65 July 27 1998,Vol.30,pp.16.

[13] Yin,R.K., "Case Study Research:Design and Methods”, Sage Publications 1994. 